\title{
MOLINOS DE VIENTO Y DE AGUA EN LAS VISTAS DE WYNGAERDE (1562-70)
}

\author{
POR \\ ANTONIO LÓPEZ GÓMEZ
}

En la antigüedad la molienda de los cereales era esencialmente realizada mediante el trabajo humano, aunque los romanos ya conocieron los molinos hidráulicos; éstos se extienden en tiempos medievales y modernos, en menor escala los de viento, artificio también empleado en algunos sitios para elevar aguas. Los aspectos generales en España han sido analizados por diversos autore ${ }^{1}$ especialmente González Tascón los primeros (10) y Caro Baroja los otros (4), en la Huerta de Valencia los de agua por Rosselló (21), en la cuenca del Tajo en tiempos de Felipe II por Arroyo Ilera (2), etc.; por nuestra parte, hemos indicado su importancia en dicho río como obstáculos en los proyectos de navegación (13) y hemos citado los manchegos $(14,15,16)$. Aquí nos referimos a un detalle, la presencia de ambos tipos de artefactos en las extraordinarias vistas de ciudades de Anthonie o Anton Van den Wijngaerde o Wyngaerde, realizadas por encargo de Felipe II, en varios viajes entre 1562-70, pocos años antes de la Relaciones Topográficas ${ }^{2}$.

1 Ya en el célebre tratado de Juanelo Turriano (ahora se discute su autoría) se dedica gran atención a los molinos (17, p. 254). En lo sucesivo los números entre paréntesis corresponden a la bibliografía final.

${ }^{2}$ Ya en prensa este artículo ha aparecido la excelente obra de F. Arroyo Ilera titulada Agua, paisaje y sociedad en el siglo XVI, según las Relaciones Topográficas de Felipe II, Madrid, Eds. del Umbral, 246 p. Supone un original y muy preciso estudio del tema en

Antonio López Gómez. Departamento de Geografía, Universidad Autónoma-Instituto de Economía y Geografía (CSIC). Madrid.

Estudios Geográficos

Tomo LX, n. ${ }^{\circ} 235$, abril-junio 1999 
Sin entrar aquí en la cuestión de una posible empresa paralela para el conocimiento del país (también el mapa de España), tales vistas, salvo alguna de Madrid, eran poco conocidas, ahora han sido estudiadas por diversos especialistas en dos grandes obras, con la dirección de Kagan las de España en conjunto (12), a las cuales corresponden los fragmentos aquí reproducidos, y la de Rosselló las valencianas con gran detalle (22), por consiguiente prescindimos de aspectos generales sobre su autor, finalidad, contenido, etc., interesantísimos pero ya expuestos en esos trabajos, así mismo de comparaciones con las vistas contemporáneas de Hoefnagel a las que dedicamos otro estudio.

Dada la extraordinaria calidad y precisión de los dibujos, así como el origen flamenco del autor, habituado a los artefactos de su tierra, no extraña que figuren los llamativos molinos de viento manchegos, sobre los cerros de un par de lugares representados, Belmonte y Chinchilla, pero tiene mayor interés aún que también se dibujen otros costeros aislados y mucho menos conocidos en Málaga, Gibraltar, Puerto de Santa María o Cádiz. Por otra parte, en diversas ciudades a orillas de ríos, aparecen así mismo molinos hidráulicos, a veces con sus ruedas verticales de paletas y las presas correspondientes. Éstas y otras diversas actividades que se reflejan, subrayan el verismo de las imágenes, como auténticas «fotografías» inigualables de la época, aunque en ocasiones el alto punto de vista sea imaginario.

\section{Molinos de viento}

Los molinos de viento tienen su lugar de elección en España en dos situaciones generales bien precisas: en llanos interiores donde los ríos son lejanos o de poco caudal y fuertes estiajes, o bien en las costas con semejantes cursos de agua, allí aprovechan además las brisas. Si es posible se localizan en algún altozano para coger mejor el viento. Esas circunstancias se dan en dos espacios bien distintos y característicos, en La Mancha y en el litoral sur y oriental, en los dos primeros casos con interesantes vistas de Wyngaerde. Aparte de los modernos molinetes metálicos, extendidos por doquier y hoy en desuso, en otras zonas costeras artefactos con velas se empleaban también para extraer agua, como los

todos sus aspectos, con numerosas reproducciones de Wyngaerde; nuestras similares líneas de trabajo (colaboración en muchos casos), explican las coincidencias. 
conocidos de Mallorca o Campo de Cartagena. Y aún habrían de añadirse ahora los destinados a producir energía eléctrica, con ensayos espectaculares en las cercanías de Tarifa y otros puntos.

\section{La Mancha}

En el amplio espacio del centro de la Mancha hay pocos ríos y hasta los principales, el Záncara y el Gigüela, afluentes del Guadiana, son de escasa pendiente, magro caudal y fuerte estiaje, incluso quedan virtualmente secos; como dicen gráficamente las Relaciones Topográficas, para moler son solo «ríos de invierno», ello obligaba a acudir en verano a los molinos del Guadiana, con parecidos problemas, aunque menores, o a los del Tajo o Júcar, más caudalosos, pero a veces a una docena de leguas o más, por tanto son hechos geográficos muy marcados. La solución era los molinos de viento, precisamente la mayoría se concentraba en el espacio entre aquellos ríos, aparte de algunos otros marginales cercanos, como el notable grupo de Consuega, al W, u otros aislados como en Chinchilla, al E.

En la quijotesca aventura, un comentario muy frecuente ha sido que eran artefactos de introducción reciente y de ahí la extrañeza para el Caballero andante, como ya detallamos en otro trabajo (14, p. 237). Probablemente eran los de Campo de Criptana, donde las Relaciones Topográficas citan «junto a la villa muchos molinos de viento» (26, Ciudad Real, p. 168, resp ${ }^{\text {a }} 23^{\text {a }}$; el Catastro de Ensenada, en 1750, menciona 34 con sus nombres (19, p. 161) y Madoz aún 24 (18, t. 5, p. 372); los de hoy son reconstrucciones en su mayoría, aunque alguno todavía conserva la vieja maquinaria de madera.

En su edición comentada del Quijote, Clemencín solo anota molinos, según las Relaciones, en El Pedernoso, en Cuenca, lo que probaría su poca difusión (4, p. 292); Blázquez también en Campo de Criptana y en Mota del Cuervo, según una visita de 1603 (3, p. 23). Se suele citar el texto de Ford que los fecha en 1575, lo recoge Azorín en La ruta de Don Quijote (1905) y se ha repetido después por García Mercadal (9, pp. 79-81), Torres Balbás (25, p. 145) y otros. A los molinos en numerosos lugares se refiere Planchuelo, sin precisar fechas (19, p. 157-62). Caro Baroja, en su documentado estudio (4), señala las citas de las Relaciones de Belmonte, Las Mesas y Villaescusa de Haro, en Cuenca (edición de Zarco), así mismo, según manuscritos, en Vi- 
llacañas, Madridejos, citas de Madoz, etc., trazando un mapa. Sin embargo señala su origen más antiguo y así menciona textos de al-Himyari sobre Tarragona, el Arcipreste de Hita, el halconero mayor de Juan II en Tordesillas, etc. aunque reconoce que «resulta verosímil que los molinos que vio Don Quijote fueran modernos en su época» y serían los de Campo de Criptana.

Aquí nos interesa subrayar que de las tres vistas de Wyngaerde de localidades manchegas, Almansa, Chinchilla y Belmonte, en las dos últimas hay representación indudable de molinos de viento y se confirma su existencia en las Relaciones Topográficas, según éstas también en otros lugares.

Belmonte.-Hay un apunte a pluma (12, p. 253), sin fecha (fig. 1); según Kagan debe ser de 1565, en el viaje a Cuenca, pero también pudiera corresponder al realizado por el reino de Aragón en 1563, en el regreso de Valencia a Madrid, al que pertenecen las vistas de Almansa y Chinchilla. Aparece con toda nitidez y dominando la ciudad «una fila de molinos» como señala Kagan; son seis, cilíndricos, con caperuza, a la izquierda de la población, además otro aislado al E. El comentarista dice «según las Relaciones Topográficas se utilizaban principalmente para proporcionar agua a las huertas y otros campos que constituían la base de la economía de Belmonte, principalmente agrícola» (12, p. 253).Re-

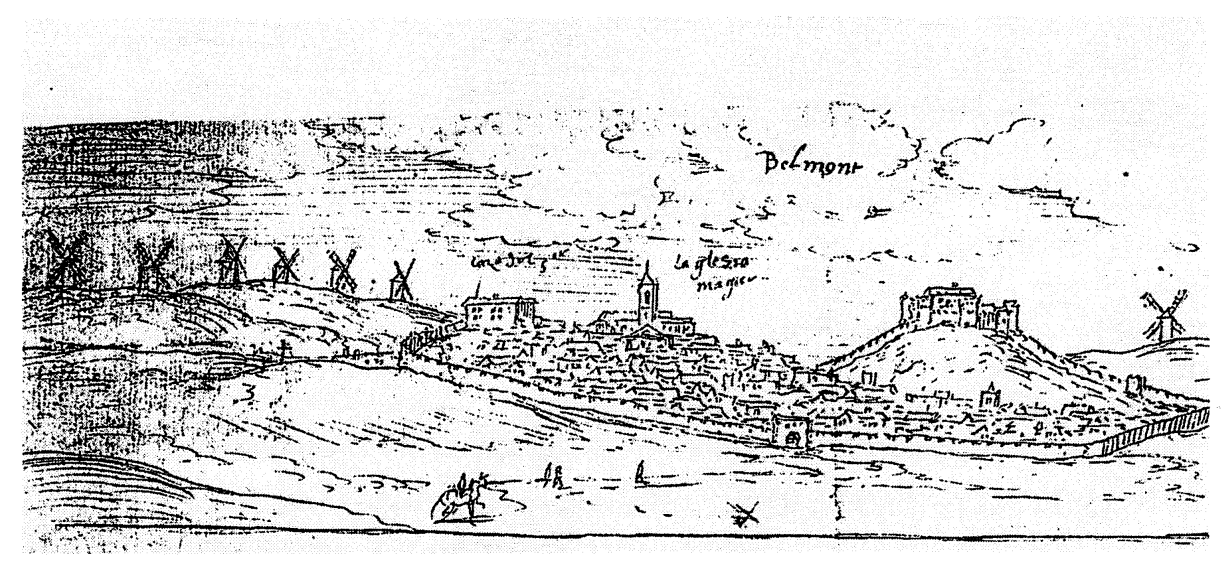

FiG. 1.-Belmonte Molinos de viento en altozanos a ambos lados de la villa, seis a la izquierda y uno a la derecha. Éste y los fragmentos siguientes de las vistas, tomados de Kagan. 
sulta extraña tal aseveración ya que los molinos están claramente en un alto, sitio muy adecuado para coger el viento pero no para extraer agua; sistema éste, por otra parte, no utilizado en Castilla entonces, que sepamos. Además la relación es terminante y diferencia dos hechos; en la respuesta $n{ }^{\circ} 21(27$, p. 180$)$ se dice que hay «muchas huertas de hortaliza que se riegan de anorias» (sic), cita luego las fuentes y añade «tiene muchos molinos de viento, con que se suple la falta de los de agua. Están en la cumbre de dos cerros que están en torno de la villa». No cabe la menor duda. Además, en la respuesta n. ${ }^{\circ} 20$ se dice que el río Záncara pasa a dos leguas y «hay en él muchas casas, de molinos. Suele faltarle el agua el estío».

Otros lugares.-La mención del estiaje y la necesidad de molinos de viento se encuentra también en otros lugares de la comarca. En Villaescusa de Haro, $2 \mathrm{~km}$ al N, se indica que en dicho río hay 10 molinos, con inclusión de nombres y propietarios, pero cuando se seca van al caudaloso Júcar, a 8 leguas, o muelen «en cuatro molinos de viento que hay en esta villa, de vecinos de ella» (27, p. 568-69, resp. $22^{\mathrm{a}}$ y $23^{\mathrm{a}}$ ).

A una decena de kilómetros al S, en El Pedernoso, las moliendas de invierno se verifican en seis molinos en un arroyo «y en otros molinos de viento que dicen», durante el verano se acude al Júcar a 9 leguas (27, p. 388 , resp. $20^{\mathrm{a}}$ y $23^{\mathrm{a}}$ ). Al SW, en Mota del Cuervo, aunque resulte extraño, no debía haber de viento todavía, ya que no se citan y en cambio se precisa que van a moler a los del Gigüela o Záncara, "ríos de invierno», a 4 leguas, pero en verano al Guadiana o Júcar, a unas 10 leguas (2, p. 368), resp. 23). Después serían numerosos ya que Madoz menciona 18 de viento (t.11, p. 624) y aún quedan algunos.

Aguas abajo, donde el Záncara tuerce al oeste, en Las Mesas, hay también cuatro molinos, dos de viento y dos de agua, de poco rendimiento, con breve descripción de sus circunstancias, también acuden a los del Júcar y otros menores (27, pp. 334-35, resp. 22 y 23); Madoz cita todavía un molino de viento (t. 11, p. 304). Finalmente en Campo de Criptana hay «junto a la villa muchos molinos de viento» (26, Ciudad Real, p. 168, $\operatorname{resp}^{\mathrm{a}} 23^{\mathrm{a}}$ ), como ya se ha indicado. No hay relaciones de Consuegra o Alcázar de San Juan, donde aún permanecen los edificios (o reconstruidos) y en el primer lugar uno mantiene la maquinaria de madera.

Chinchilla.-Se conserva un borrador, un boceto algo distinto y, sobre éste, se hizo el dibujo final (12, pp. 215-218), fechado en 1563. En la vista (fig. 2) tomada desde el $\mathrm{E}$, en el cerro y a la derecha del castillo,

$$
-307-
$$




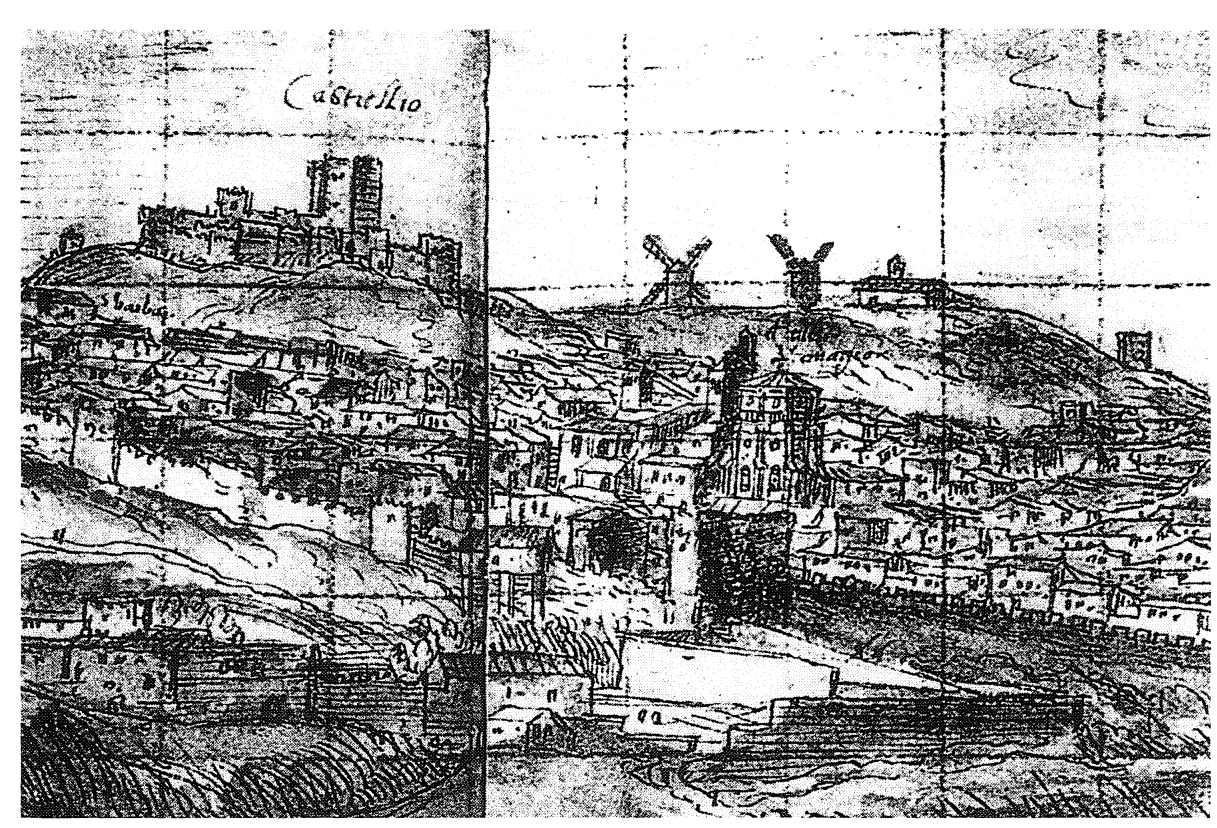

FIG. 2.-Chinchilla. Izquierda de la vista general. Molinos de viento al pie del castillo.

aparecen muy destacados por su tamaño dos molinos de viento, cilíndricos, con caperuza y cuatro aspas, éstas faltan en uno del borrador. Según Kagan «los molinos situados en la cresta de la colina indican algún tipo de actividad económica» (op. cit., p. 214), sin precisar más.

En la relación, de 1576, se citan molinos del Júcar y se añade que «tiene esta ciudad dentro del cuerpo della dos molynos de viento que son del conçejo» (6, p. 120, resp. 22 y 23), sin duda son los dibujados en la vista.

\section{Costa andaluza}

Es bien conocida la frecuencia y fuerza del viento en la zona del Estrecho de Gibraltar. Ello explica la presencia de molinos de tal clase en cuatro lugares con vistas de Wyngaerde: Málaga, Gibraltar, Cádiz y Puerto de Santa María; la primera es de 1564, cuando se preparaba la expedición al Peñón de Vélez de la Gomera, las otras del viaje por Andalucía y Extremadura en 1567. Posiblemente hubiera en más lugares, 
por ejemplo aún quedan restos de varios en Vejer de la Frontera, pero no disponemos de representación y Madoz sólo cita molinos harineros sin especificar (t. 15, p. 638). En cambio no figuran en las vistas de Tarifa, Zahara ni Sanlúcar. Como ya apuntamos, en el Estrecho mismo, en los montes de Tarifa se encuentra hoy un llamativo «campo» de torres metálicas con tres aspas para obtener energía eléctrica, novísima reutilización de un recurso perenne.

Existieron también artefactos en las costas valencianas meridionales (6 bis, pp. 498-501), pero no aparecen en las vistas de Valencia o Sagunto; tampoco en las de Tortosa, Tarragona o Barcelona. En cambio eran numerosos en Mallorca, « la isla de los molinos» la llama Rosselló (20, pp. 408-11), aparte de los destinados a extracción de agua en esta misma (20, pp. 332-34) o en el Campo de Cartagena.

Málaga. - La vista está tomada desde el SE (12, pp. 220-22). Sobre la extensa ciudad amurallada, en el centro, a la derecha y detrás de la torre de la iglesia de San Francisco (O), en la ladera del monte, parece dibujarse un molino con sus aspas. También en el extremo izquierdo, un edificio casi imperceptible lleva la indicación «Y», según la cartela es «La Torra de molyno», hoy Torremolinos (Kagan, p. 220), lo que parece aludir a un artefacto aunque aquélla fuese ya de vigilancia como otras de «la Reina» (V) y Zambra (X), en lo alto del monte, en la parte central, indicadas en la leyenda y de tal función según Kagan (p. 220).

Madoz únicamente menciona molinos de agua y curiosamente, uno de vapor, en la ciudad (t. 11, p. 88) ${ }^{3}$.

Gibraltar.-Es una magnífica vista desde el NW (12, pp. 389-90). Al pie del acantilado, en el istmo, junto a la «torre del Diablo» (F) hay un molino perfectamente delineado con las aspas atrás (fig. 3).

Puerto de Santa María.-En la vista desde el SE, con todo el primer término ocupado por salinas, hacia el fondo, en la parte izquierda, junto a la ermita de Nuestra Señora de Guía (B), en el dibujo definitivo (12, p. 312) aparece claramente un molino prismático de grandes aspas (fig. 4); es menos visible en el boceto y con rótulo ilegible, quizás «molin» (p. 311 arriba). Aún se vislumbra en un apunte, pero allí en la parte derecha ya que está tomado desde el NW (pp. 309-10). No hay referencia a molinos de ningún tipo en Madoz (t. 13, p. 283).

${ }^{3}$ En Torremolinos Madoz, sin indicar que sean de viento, cita 14 molinos harineros (t. 15 , p. 95). 


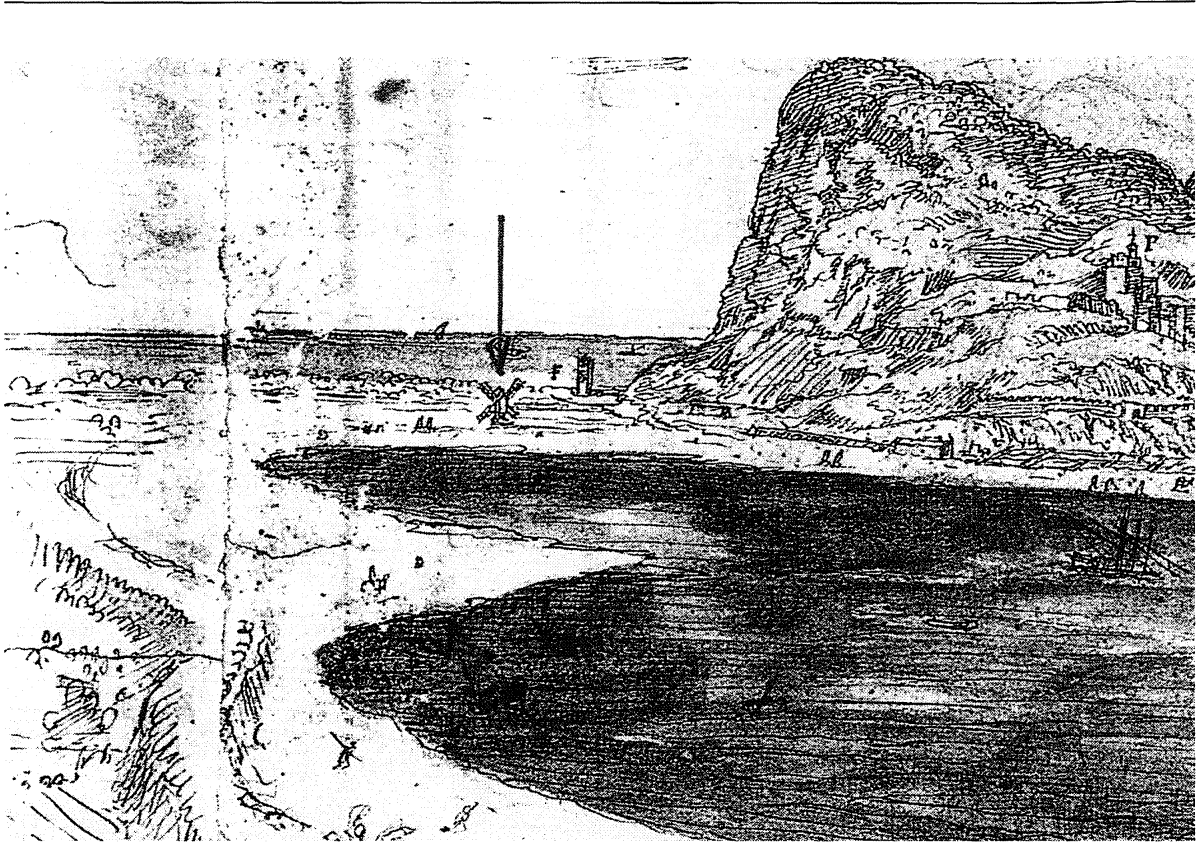

FIG. 3.-Gibraltar. Izquierda de la vista general. Molino de viento al pie del peñón, se indica con flecha.

Cádiz._En la vista, desde una elevada perspectiva imaginaria al NE de la ciudad, a la derecha de la lámina (12, pp. 302-304), junto a S. Francisco $(\mathrm{P})^{4}$ y próximo al mar, se dibuja perfectamente un molino de viento prismático con techo a dos aguas (fig. 5); ya aparece en el boceto (p. 306). Madoz dice que la mayor parte de la harina se hacía en las tahonas, además dos molinos muy buenos en el río Arilla y uno de vapor en la ciudad misma (t. 5, p. 186).

\section{Molinos fluviales}

Conocidos ya desde época medieval, con citas catalanas de los siglos VIII-X (21, p. 317), en la obra de González Tascón (10) han sido bien estudiados sus tipos que no vamos a repetir aquí; únicamente re-

${ }^{4}$ Este convento, recién fundado, se perdió en el ataque de los ingleses en 1596 (12, p. 301). 


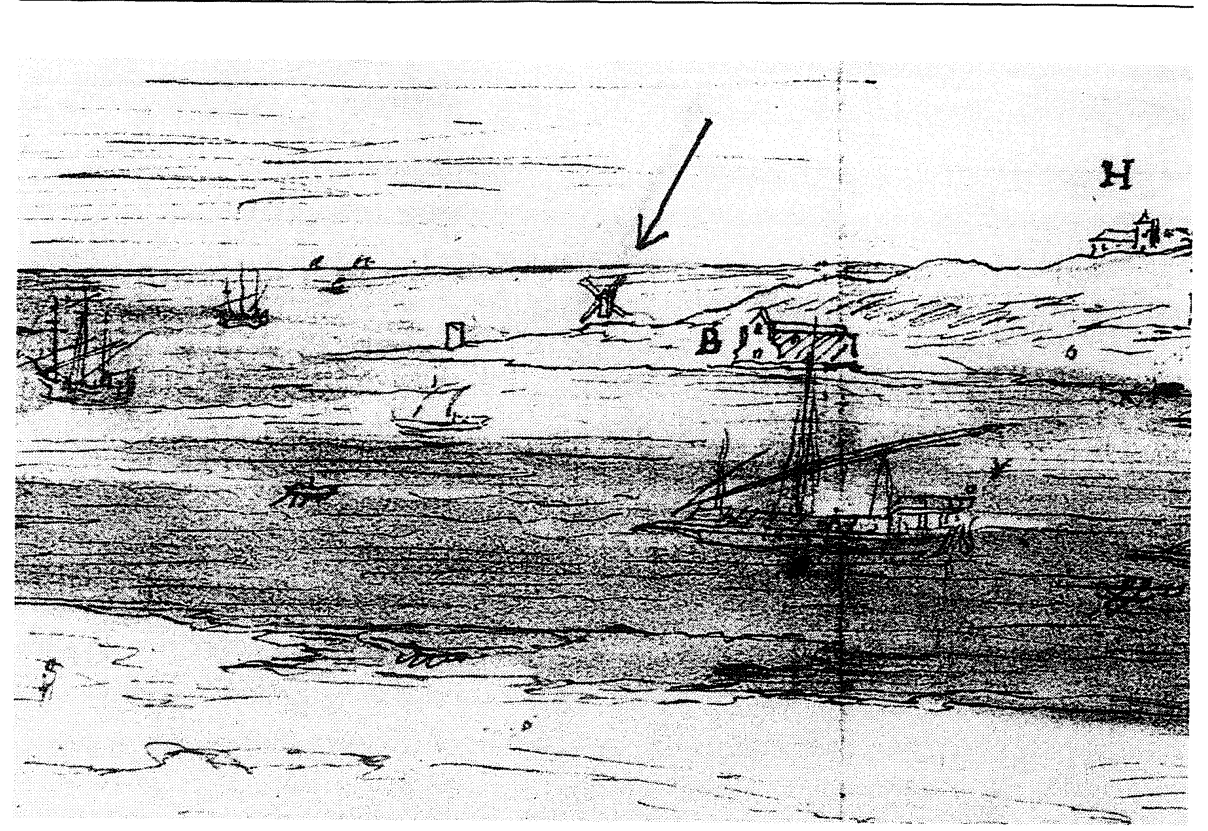

FIG. 4.-Puerto de Santa María. Izquierda de la vista general. Molino de viento junto a la orilla, indicado con flecha.

cordaremos algunos rasgos generales que se reflejan en las vistas de Wyngaerde. Como éstas se refieren a localidades destacadas a orillas de ríos grandes o medianos (acequia importante en un caso), el caudal es suficiente, no se precisa canal para ganar altura y el artefacto se sitúa junto a la corriente, inmediato a ésta o en ella misma y con la presa correspondiente, de piedras y tierra, es decir del tipo usualmente llamado «aceña». El movimiento se obtiene por rueda vertical de paletas que aparece dibujada en muchos casos (a veces poco visible), aunque algunos podrían ser de rodezno. La representación, con edificios rectangulares a dos aguas, es parecida a las numerosas que figuran en el curso del Tajo según el reconocimiento de Carduchi de 1641 que hemos estudiado en otro lugar (13).

Indicamos una quincena de casos, distribuidos en cinco grupos: Submesetas norte y sur, valles del Ebro y Guadalquivir y Huerta de Valencia.

$$
-311-
$$




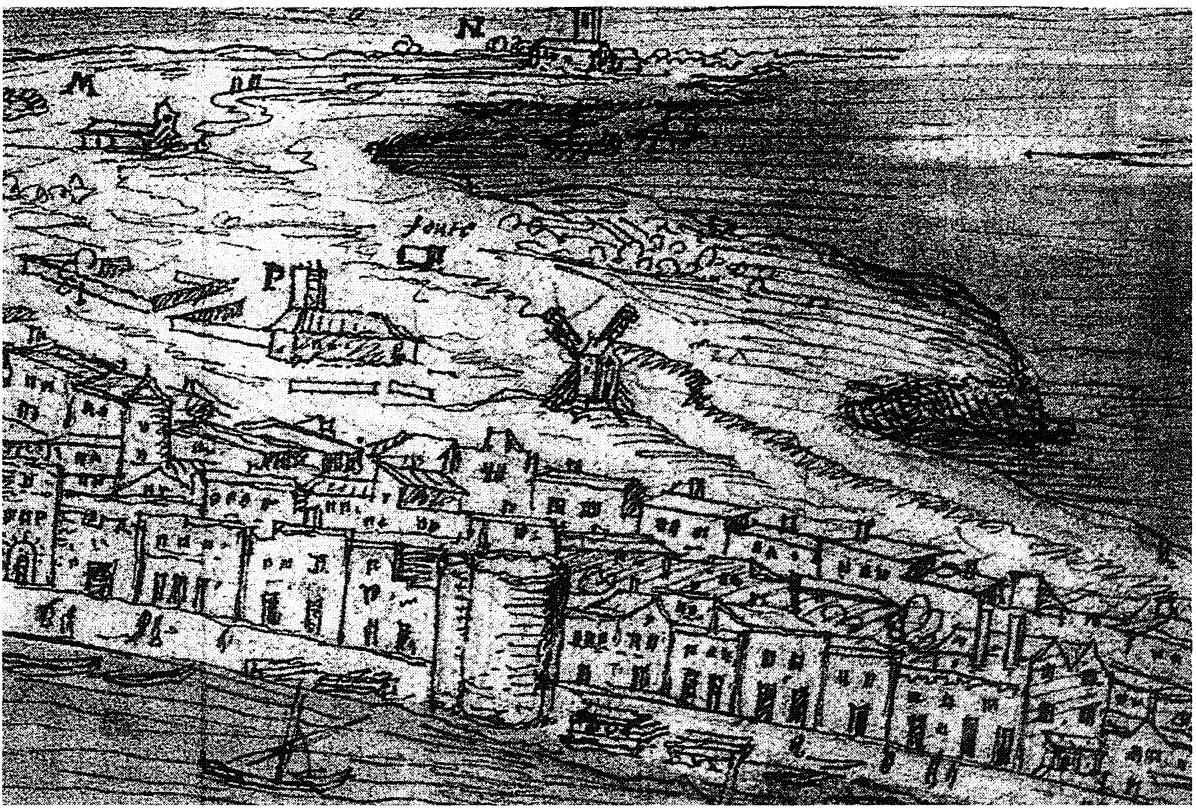

Fig. 5.-Cádiz. Derecha de la vista general. Molino de viento junto a la orilla.

\section{Submeseta Norte}

En dos viajes, en 1565 y 1570, Wyngaerde representa diversas ciudades junto a ríos e indica molinos con precisión en el Duero en Tordesillas, Toro y Zamora, también Madoz (t. 15, p. 26 y 40, t. 16, p. 487); en Salamanca y Alba de Tormes en este río (Madoz sólo en la primera); en el Eresma en Segovia y posiblemente en el Adaja en Ávila (no cita Madoz); el boceto de Valladolid es bastante confuso para nuestro objeto; no figuran en Burgos.

Tordesillas.-Sólo hay un boceto (12, pp. 380-81); en la parte izquierda una presa que parece en zig-azag con cinco edificios en línea, sin rótulo; en el central se vislumbra la rueda.

Toro.-Vista desde el NW (12, p. 376-78), en la otra orilla; a la derecha, en el meandrinoso curso, con grandes islas (aún hay en la actualidad), entre «M. $\mathrm{Nr}^{\mathrm{a}} \mathrm{Sr}^{\mathrm{a}}$ de la Vega» y el gran puente se percibe mal «molynes» y apenas los edificios. En cambio, después del puente (fig. 6) 
se dibuja claramente una presa y en su extremo, con el rótulo «molynes», un muro con seis construcciones rectangulares en línea, en una se percibe la rueda, en las otras la salida del agua.

Zamora.-En la derecha de la lámina (pp. 370-72), antes del puente hay una larga presa curva, cóncava hacia aguas arriba y con el rótulo «tyera» (tierra, para indicar su material) ${ }^{5}$; en su centro «Molynes», con muro y tres edificios delante, en uno de ellos, sobre pilotes, se aprecian la salida de agua y la rueda. A la izquierda, junto al puente viejo arruinado, otra presa con dos edificios y en uno de ellos la rueda (fig. 7).

Segovia.-Hya dos vistas, por el NE y por el SW. En la primera (12, pp. 124-25), en el Eresma, en primer término, junto a un puente dos edificios perpendiculares a la orilla muestran la rueda característica; es menos visible en otro de un grupo a la izquierda.

En la otra, más amplia (pp. 127-29), a la derecha hacia el fondo, junto al puente, un edificio bajo y otro alto con el rótulo «molin».

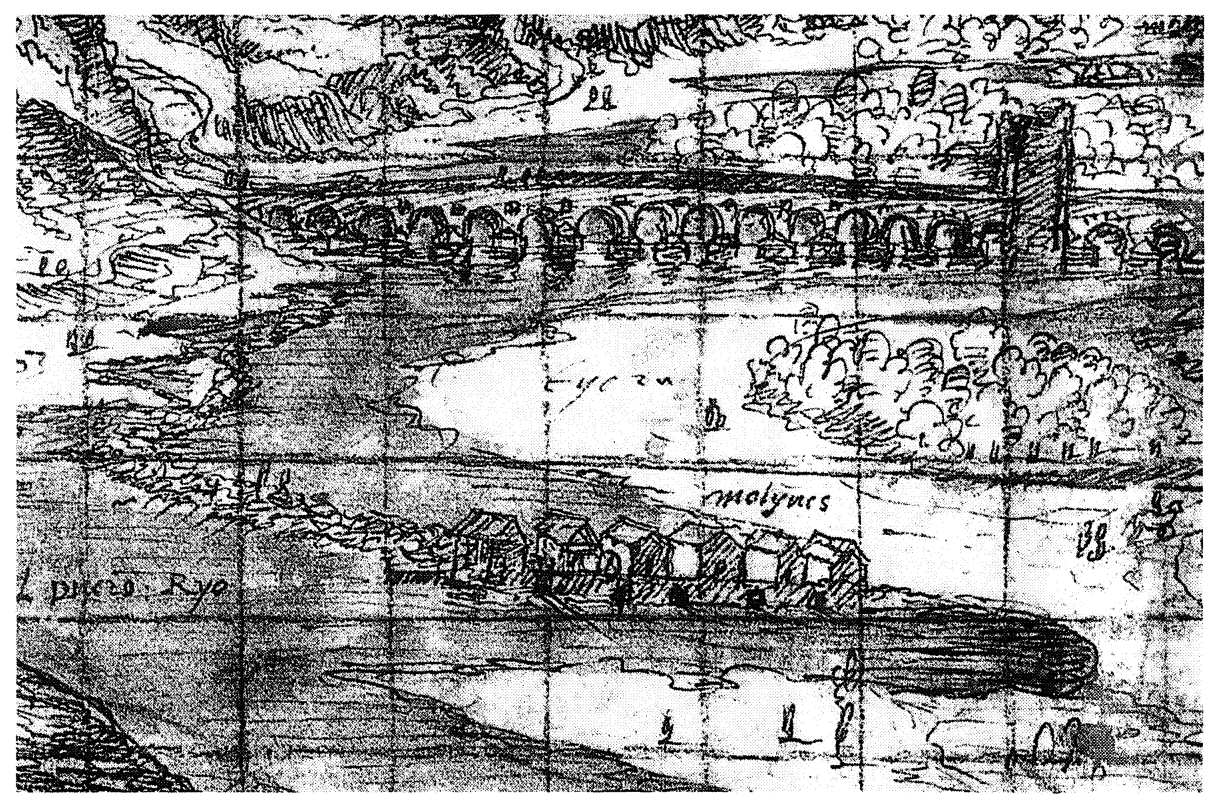

FIG. 6.-Toro. Derecha de la vista general. Grupo de seis molinos («molynes») con presa sobre el Duero.

${ }_{5}^{5}$ También ese rótulo en una isla del puente.

$$
-313-
$$




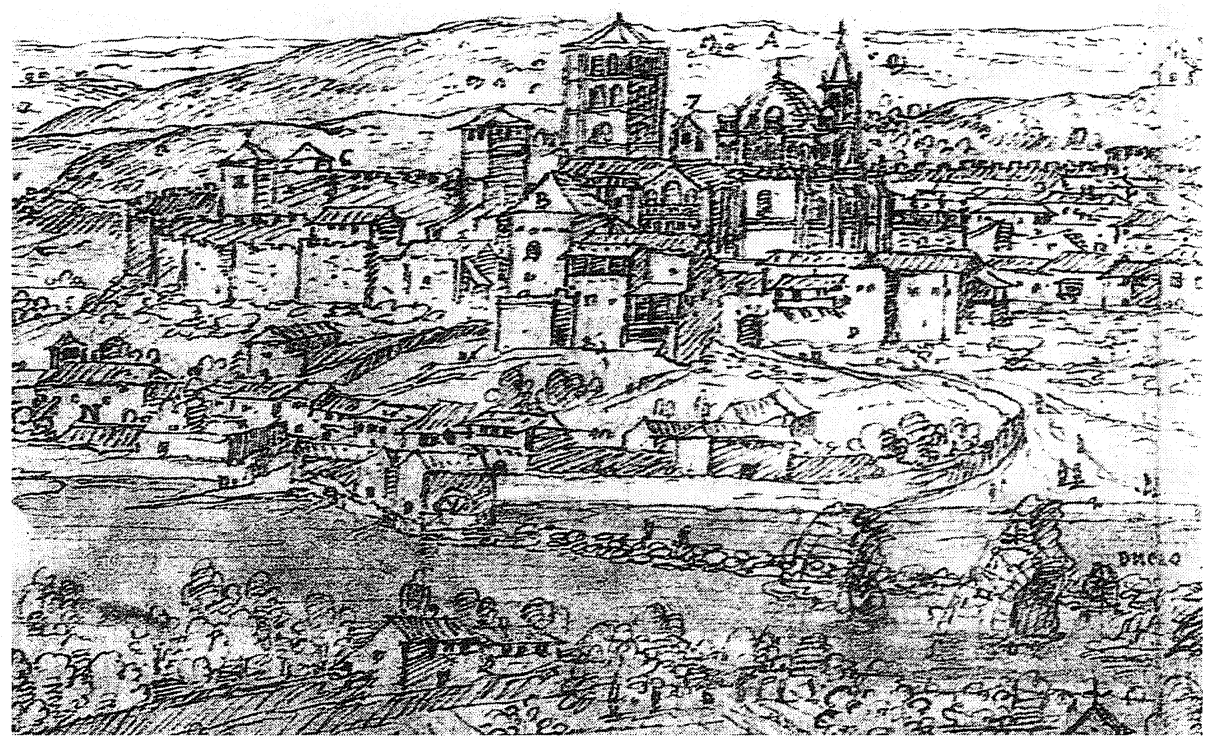

Fig. 7.-Zamora. Izquierda de la vista general. Presa y molinos (se ve la rueda) junto al puente viejo, derruido (arranque de arcos), sobre el Duero

Ávila.-Vista desde el SW. En el centro izquierda (pp. 356-58), junto al viejo puente romano (hoy arruinado) con un rótulo «water» y la desembocadura de un arroyo afluente en el Adaja, allí recto y mal precisado (a la derecha rótulo «Ryo»), hay una construcción perpendicular sobre el río, probablemente un molino.

Alba de Tormes.-En el amplio dibujo (pp. 359-61), cerca de la puerta meridional de la muralla (a la izquierda, rótulo «porta») aparece un molino con su represa, como señala el comentarista (12, F. Marías, p. $362)$; es recta y en el extremo se ven dos edificios con sus ruedas. Pero además, a la derecha del puente y muy próximos a éste, hay otros dos, se vislumbra una rueda y apenas se ve la presa.

Salamanca.-En la gran vista desde el otro lado del río Tormes (12, pp. 364-66) indica F. Marías (p. 363) la presencia de «un molino con su presa», efectivamente aparece el largo azud curvo cruzando el ancho río en azul y en sus extremos, muy bien dibujadas, dos edificaciones sobre pilotes, con tejado a dos aguas y paredes entramadas, en la de acá el 
rótulo «molynes» (fig. 8). Pero además, en el borde izquierdo y algo desdibujados, parecen diseñarse dos presas con edificios que serán igualmente molinos.

Valladolid.-En el dibujo preparatorio de conjunto (12, pp. 390-92), desde el otro lado del río, éste discurre recto por en medio, poco visible aunque lleva algunos rótulos «water»; junto a uno de ellos, a la derecha del puente (en el centro) hay tres edificios unidos y parece vislumbrarse una rueda, podrían ser molinos; así mismo otros diversos inmediatos al río. Madoz cita «infinidad de molinos y aceñas» (t. 15, p. 872).

\section{Submeseta Sur}

En las vistas de un corto viaje, en 1565, se encuentran molinos en el Henares en Alcalá, posiblemente en Guadalajara (no citados por Madoz) y claramente en Cuenca en el Júcar; al viaje de Andalucía y Extremadura en 1567 corresponde la expresiva imagen de Talavera de la Reina; en To-

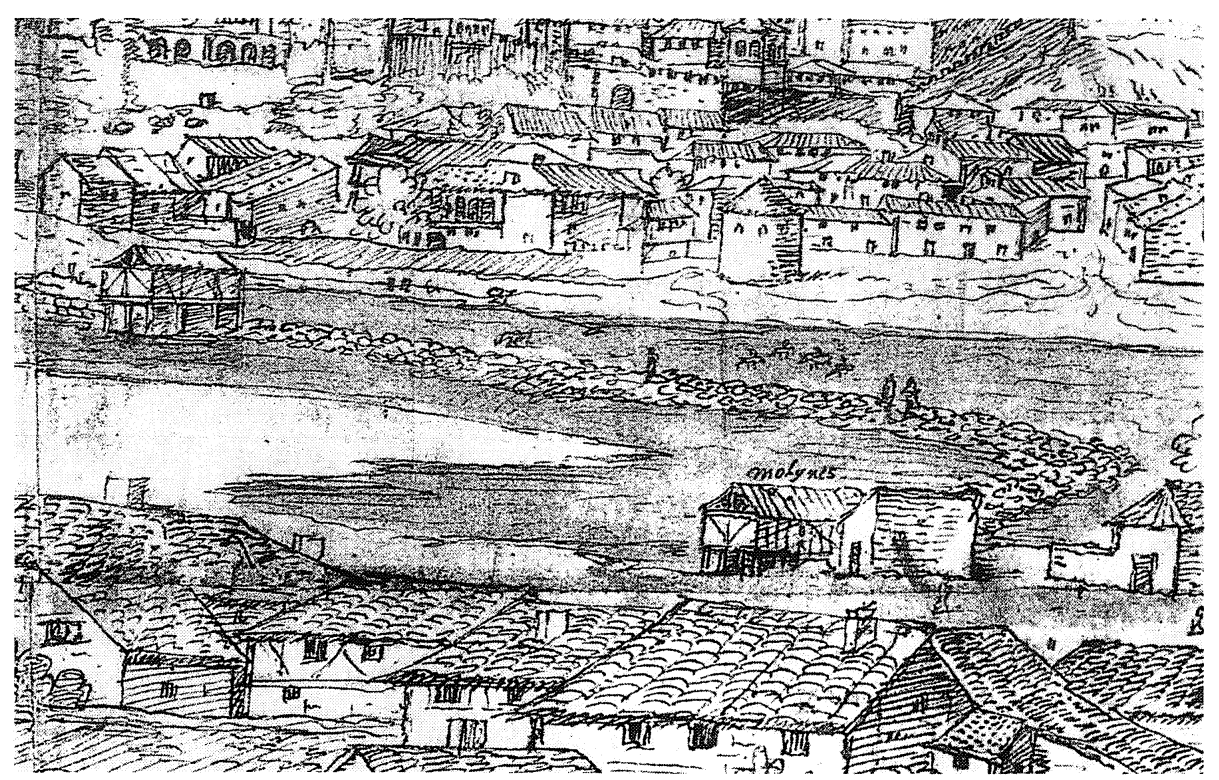

Fig. 8.-Salamanca. Derecha de la vista general. Presa de piedras y dos molinos (en uno rótulo "Molynes») sobre pilotes en el Tormes. 
ledo figuran azudas pero no molinos. No incluimos aquí, lógicamente, la indicación de unos «molynos de aseta» 0 aceite en las afueras de Guadalupe (12, pp. $342-44$, centro) que serían movidos por caballerías ${ }^{6}$.

Guadalajara.-En una vista desde el W, con el ancho y recto Henares en primer término (12, pp. 240-42), el puente muestra alta torre en medio mientras que en los extremos, adosados aguas abajo, dos edificios rectangulares probablemente son molinos.

Alcalá de Henares.-En la vista desde el W (12, pp. 234-36), al fondo aparece el río, al pie de los cerros. A la derecha edificios borrosos con claro rótulo «molino», en el centro, en otros, también parece leerse «molinos».

Toledo.-En la magnífica vista desde el N (12, pp. 132-34) queda oculto el torno del Tajo, donde había varios artefactos; en cambio, antes de la entrada, a la izquierda (fig. 9), aparecen dos altas ruedas, sin edificios, obviamente no son de molinos, sino azudas para elevar el agua a las huertas inmediatas, según se indica en las Relaciones Topográficas (26, Toledo III, pp. 501 y 503) y son similares a las que se representan aguas abajo en el reconocimiento de Carduchi de 1641, indicado en otro trabajo (13, figs. 5 y 8 y p. 103). En la otra orilla se distinguen maderos de los que bajaban por el río y se aserraban en la ciudad. También aparecen ruedas en el proyecto de Simón Pontero de 1755 (13, figs. 72 y 73) y «norias» en el de Cabanes de 1829 (figs. 82-83). Ahora se intenta montar una nueva como recuerdo.

Talavera de la Reina.-Vista desde la orilla sur del Tajo (pp. 349-52), con varias islas antes y después del puente (pasarelas en varios arcos derruidos); en el centro, adosados aguas arriba hay tres edificios sin nombre (fig. 10), sin duda son molinos porque en las Relaciones Topográficas, entre los diversos del sector, se citan «cerca de la villa, en la puente de ella hay otros que son de los propios de la villa» (26, Toledo II, p. 449) y en el reconocimiento de Carduchi de 1641, para navegación, se rotulan así dos construcciones en la misma posición (13, p. 105 y figs. 2426, allí el E a la derecha). Figuran tres en el proyecto de Simón Pontero de 1756 (13, fig. 76 y p. 136), pero ya no se encuentran en el de Cabanes de 1829, otros aguas abajo (13, fig. 85 y p. 167); Madoz menciona dos paradas de molinos pero sin especificar sitio (t. 14, p. 570).

\footnotetext{
${ }^{6}$ Por lo que se destacan, debían ser importantes; inmediata una larga caballeriza ( «La Caualeryza»), posiblemente para su servicio, aunque Kagan la vincula a las necesidades de los peregrinos (12, p. 341).
} 


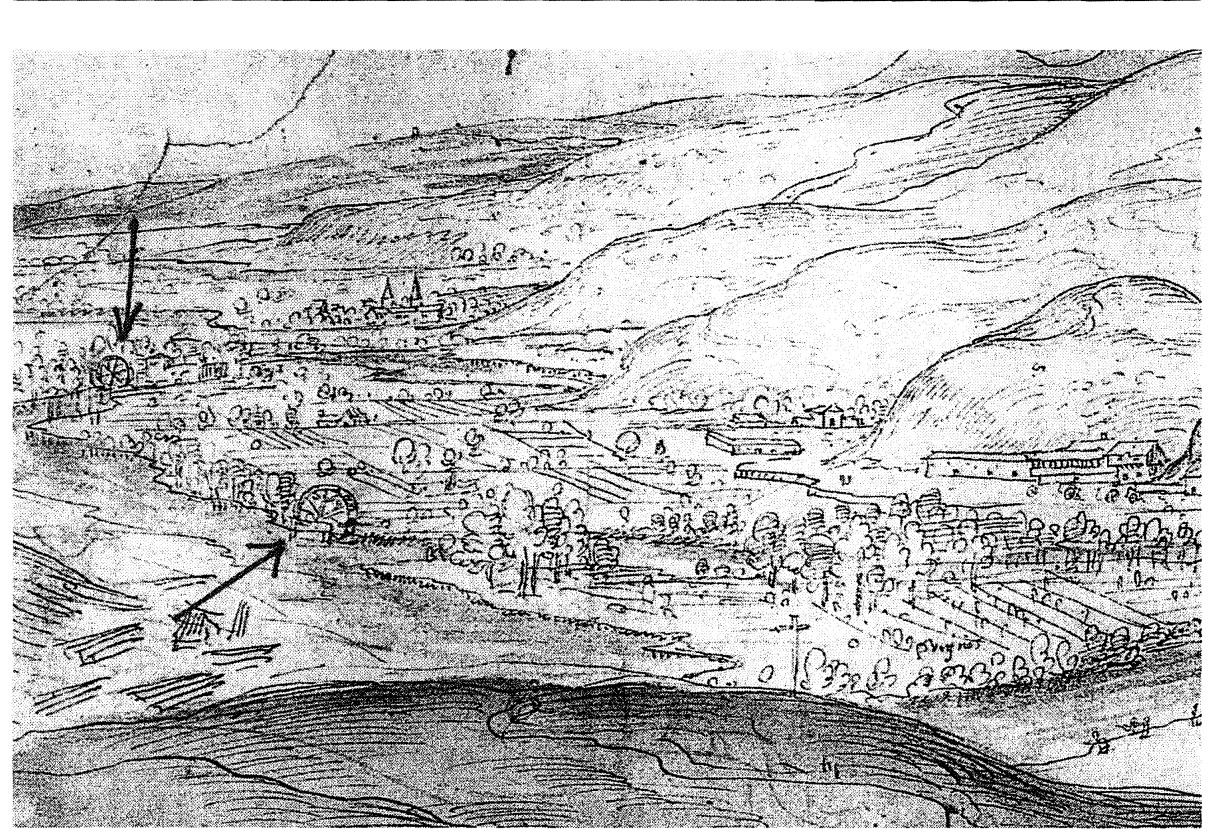

Fig. 9.-Toledo. Izquierda de la vista general. Antes del torno del Tajo, dos azudas para elevar agua, se indican con flechas; maderas en la orilla.

Cuenca.- - Hay dos vistas magníficar, por el W y E. En la primera, desde abajo (12, pp. 246-48), el Júcar sale de la hoz, forma un meandro y pasa a primer término, rotulado «el Sucaro F(lumen)». En la parte derecha, en la orilla, como señala Kagan (p. 243), un «Molin lanera o (lanatera»); las tiras en colores rosa y azul serán de tela, puestas a secar y el artefacto, en realidad, un batán. Muy cerca, en el borde «Los lauaderos de lana genouesas» (Kagan transcribe «lavanderías»); todo en relación con los entonces floreciente industria local de paños. Otro aspecto curioso que señala son los maderos que bajan por el río (desde la Sierra) y luego están apilados en la orilla. Pero hay más, en la parte izquierda cerca del puente, a la salida de la ciudad, con gran caz (que sigue aguas abajo), junto a un edificio está otro rótulo de «molino» en un recinto con figuras que parecen tender tiras también coloreadas, con la indicación de «pagnes» o paños y el llamado molino, que sería un batán.

En la otra vista, desde el E (pp. 249-51), con el río Huécar y el alto puente en construcción (sustituido por el de hierro en el siglo XIX), en el 


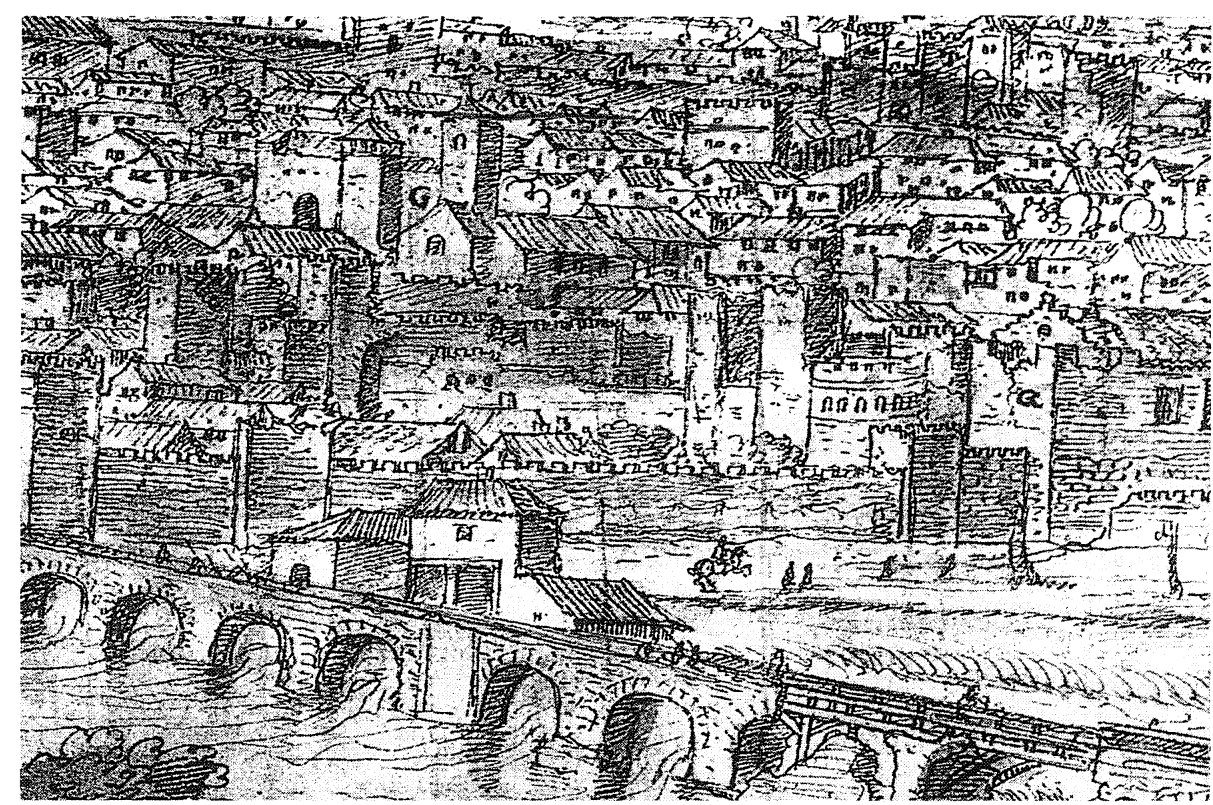

FIG. 10.-Talavera de la Reina. Derecha de la vista general. Molinos en el Tajo adosados al puente (en reparación) aguas arriba.

extremo izquierdo de la hoz hay edificios en el río que pudieran ser molinos pero no se rotulan.

Sin precisar río, Madoz cita 3 molinos harineros, además de la antigua fábrica de paños a orillas del Júcar (t. 7, p. 234).

\section{Andalucía}

Entre las numerosas vistas de ciudades andaluzas, aparte de los molinos de viento costeros, ya citados, sólo encontramos fluviales en Córdoba y Antequera; son discutibles dos ruedas que figuran en Sevilla.

Antequera.-Imagen desde el E (12, pp. 279-80). En primer término parece vislumbrarse una corriente de agua, en el extremos derecho un rótulo quizás sea «water», utilizado en otros casos; a la izquierda dos edificios rectangulares con tejados a dos aguas, situados en ángulo, con la indicación «T», correspondiente a «Molinos», según la cartela. Sin em- 
bargo Kagan (p. 281) da una interpretación peculiar como «referencia a la fuente de riqueza de la ciudad» y recoge la mención de Pérez de Mesa sobre «veinte molinos, que abastecían de agua» a huertas, viñas y sembrados; parece aludir a artefactos de elevar agua para riego. En realidad son hechos distintos, como señala Madoz el río de la Villa surte a ésta, da movimiento a molinos harineros y batanes y riega parte de la vega (12, t. 2, p. 337).

Sevilla.-En un boceto de Sevilla (12, p. 333-34), en primer término a la izquierda, en el puente de barcas, sobre la cuarta y quinta, se halla una gran rueda de paletas (fig. 11), sin más artificios visibles, podría ser para uno de ese tipo flotante peculiar, aunque forzada la posición de la rueda perpendicuar a las barcas y a la corriente ${ }^{7}$.

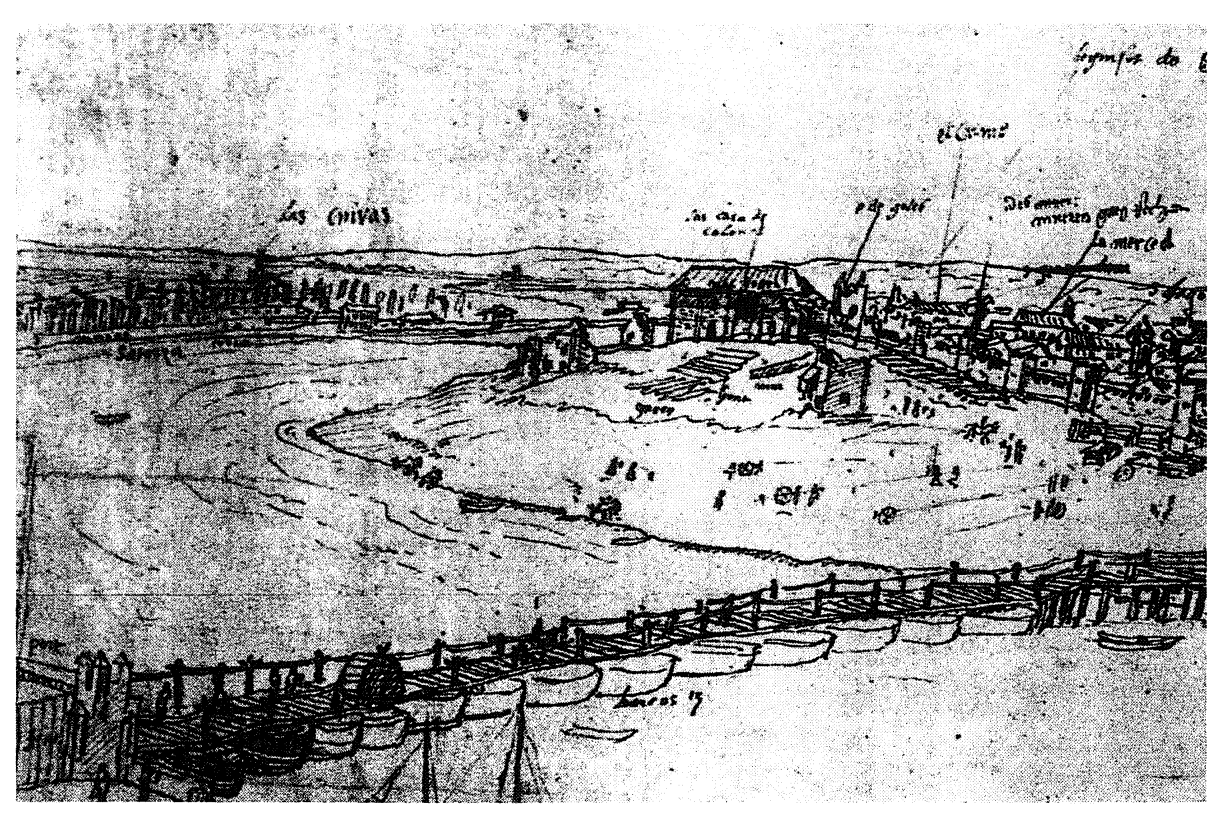

FIG. 11.-Sevilla. Izquierda de la vista general. Puente de barcas en el Guadalquivir, sobre el extremo rueda de paletas, ¿molino flotante?

${ }^{7}$ Nuevamente, a mediados del xvIII, el ingeniero Francisco Llobet proyectó un molino en el Guadalquivir sobre barcos «para moler trigo con el solo movimiento del agua del río» (18 bis, p. 79 , nota 32$)$. 
En un dibujo final de Triana desde la otra orilla (pp. 330-32), a la izquierda (fig. 12), cerca de la plazuela del Carbón y una gran torre aislada que parece la de $\mathrm{Oro}^{8}$, hay una rueda junto al río, no se ve edificio y podría ser una azuda para elevar agua o más bien, por el brazo diagonal, una grúa.

Córdoba.-En la vista, desde el otro lado del Guadalquivir (12, pp. 257-60), aparecen varios artefactos como ya apunta Kagan (p. 255). En el extremo derecho un azud recto y en la orilla de la ciudad un edificio, n. ${ }^{\circ} 13$, «Los molynos del Rey», también llamados «de Martos» ${ }^{9}$. Aguas abajo del puente, con presa angular, una fila de tres molinos, documentados del siglo xIv, «todavía existen, en condición parcialmente ruinosa» (p. 255); en la vista aparecen claramente dos edificios con su

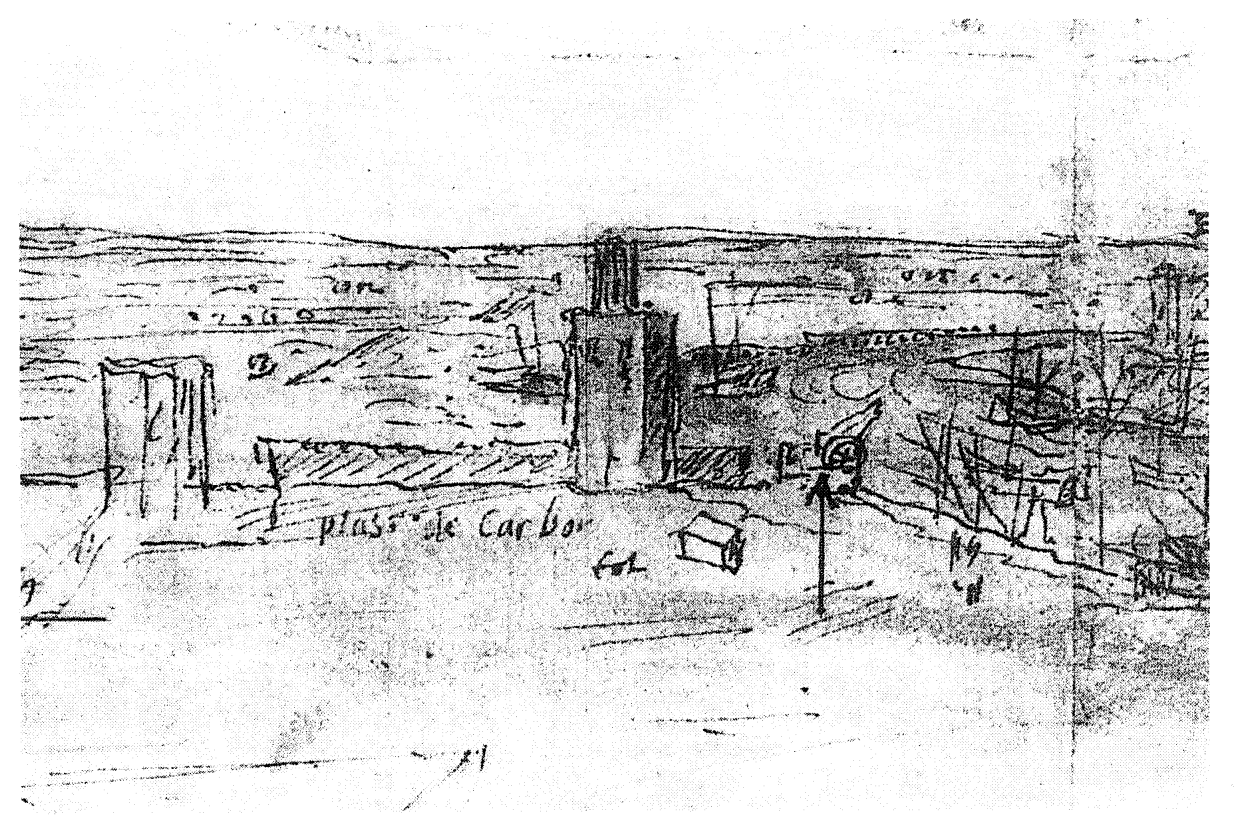

Fig. 12.-Triana. Izquierda de la vista general. Al pie de la torre se vislumbra una rueda (flecha) ¿azuda? ¿grúa?

${ }^{8}$ Junto a la Puerta del Carbón señala Madoz esta torre «parecida en un todo a la del Oro» (t. 14, p. 388).

${ }^{9}$ Este nombre (Martos) y los otros molinos citados como árabes ¿tomados de la Guide Bleu. Espagne?, vid. ed. 1957, p. 669, y plano pp. 670-71. 
rueda, en medio y en la orilla, en la otra uno grande y macizo, a manera de torre, también con rueda (fig. 13). Ha de añadirse, en el extremo izquierdo otro molino en el cual se ve peor la rueda. Otra actividad muy importante junto al río es la de los curtidores (famosos los «cordobanes» $\mathrm{y}$ «guadamecíes»), como indica el n. ${ }^{\circ} 14$ «cortydores». Madoz cita seis fábricas, así como once molinos (t. 6, p. 641).

\section{Valle del Ebro}

En dos lugares, Zaragoza y Tortosa, hay edificios junto al Ebro pero no parecen molinos; en cambio sí se encuentra uno en Lérida, a orillas del Segre. Corresponden al viaje al Reino de Aragón en 1563.

Zaragoza.-En la vista desde el otro lado del río (12, pp. 147-49), en el centro del puente aparece un edificio colgado; no es molino, con el rótulo «c. alcalde de sal...», según el comentarista Kagan son «las casas

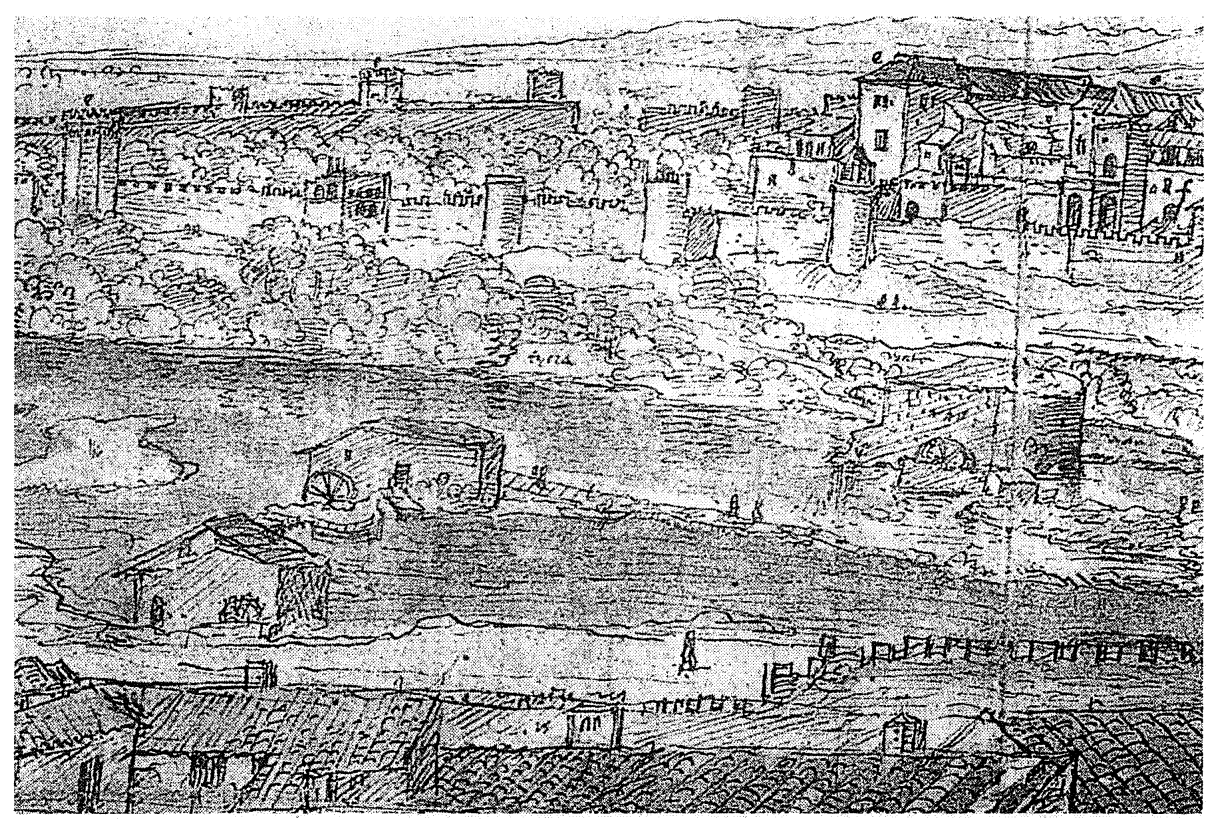

Fig. 13.-Cordoba. Izquierda de la vista general. Presa en ángulo con molinos y ruedas. 
colgadas que servían de guardia y aduanas» (p. 142). Aguas arriba, en el extremo izquierdo, en la orilla se ven maderas y obreros trabajando.

Tortosa.-En la vista desde el SW (12, pp. 182-84), del otro lado del río, no se ven artefactos hidráulicos. En la otra, desde el N (pp. 185-86, también en el boceto), dentro del recinto amurallado, a la derecha, hay un espacio abierto y en el centro una cerca con rueda claramente dibujada, será una noria, como indica el comentarista Marías (p. 181).

Lérida.-Aquí no hay duda. En la vista, desde el SE, del otro lado del Segre (12, pp. 256-58), a la derecha aparece una larga isla y en la orilla un solitario edificio rectangular a dos aguas, con rueda y debajo, poco visible, el rótulo «molin». No menciona Madoz.

\section{Huerta de Valencia}

En las tierras levantinas, aparte de utilizar para la molinería los cursos de agua secundarios, en las grandes huertas de los principales la distribución del agua para el riego era el hecho fundamental y los artefactos han de localizarse en las acequias de suficiente caudal y fluir continuo o frecuente. Ejemplo destacado, único en las vistas de Wyngaerde, es Valencia.

En la espléndida imagen de la ciudad, en 1563, desde el $\mathrm{N}$ del Turia (12, pp. 205-207; 22, entre p. 105), se dibujan claramente dos molinos en una acequia (¿la de Mestalla o una hijuela?), como señala con precisión M. ${ }^{a}$ Jesús Teixidor (23, pp. 97-98); en este caso sin presa. En la parte inferior, a la derecha (fig. 14), aparece con todo detalle una gran construcción con un torre, el rótulo «molin» y al costado el edificio (allí la firma y fecha) con la rueda vertical en la acequia (ampliaciones en 22, pp. 15 y 45). Menos destacado, en el extremo izquierdo, delante del gran palacio del Real, hay un edificio pequeño, perpendicular sobre la acequia, con la entrada del agua, sin duda otro molino (22, ampliación figura p. 123).

Los de la Huerta de Valencia en general han sido estudiados con toda exactitud por Rosselló, citando ya el de Wyngaerde (21, pp. 320-21); en aquélla se encontraba, sin duda, la mayor concentración, casi medio centenar según el Repartiment, más de una treintena entre 1421-75 según Arroyo (1), incluso una docena en la misma ciudad (23); aunque eran esencialmente harineros, también había para descascarar el arroz y al- 


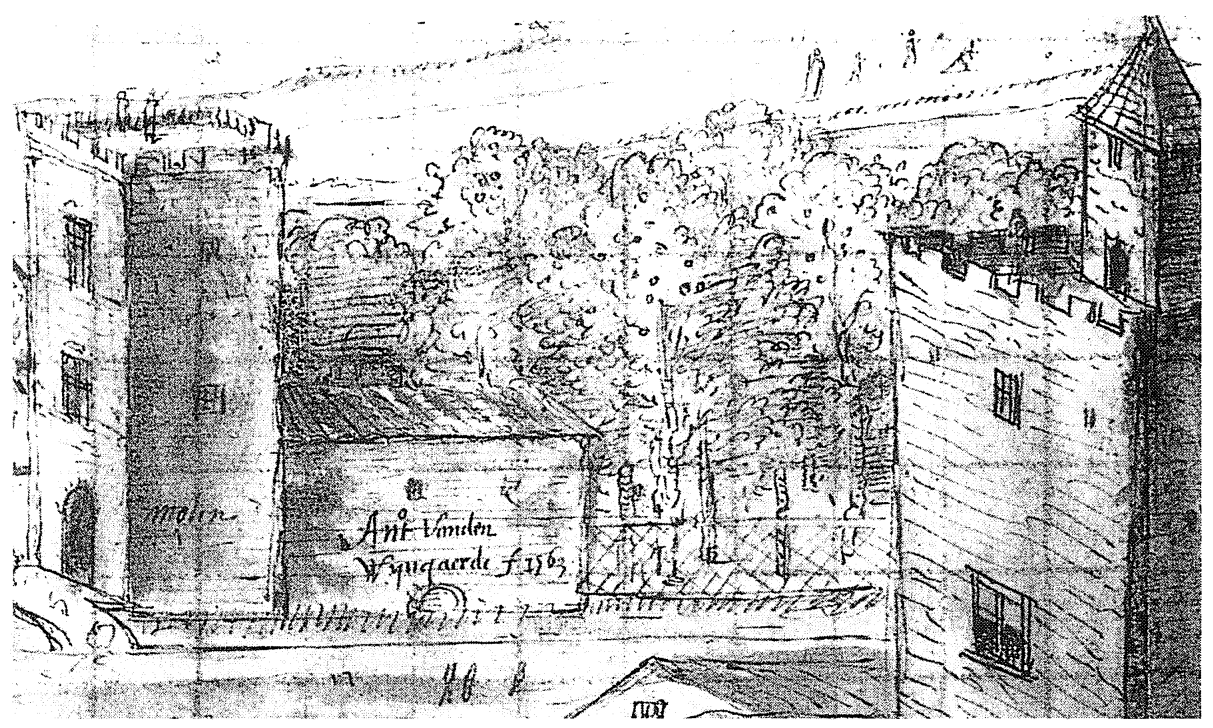

Fig. 14.-Valencia. Derecha de la vista general. En la margen $N$ del río, molino con rueda sobre una acequia (sin presa), en la pared firma de Wyngaerde y fecha.

guno de sal, en Burjasot y Tabernes Blanques (21, pp. 328-29); rebasaban el centenar en el siglo XIX y ahora apenas queda alguno pero ya utilizando otro tipo de energía.

\section{BIBLIOGRAFÍA}

(1) Arroyo Ilera, F. (1986): «Población y poblamiento en la Huerta de Valencia a finales de la Edad Media», Cuadernos de Geografía, n. ${ }^{\text {os }}$ 39-40, pp. 125-155.

(2) - (1990): «Los molinos del Tajo en el siglo Xvi según las Relaciones Topográficas de Felipe II», Estudios Geográficos, Homenaje a Julia López Gómez, n. ${ }^{\circ s}$ 199-200, pp. 259-272.

(3) BlÁZquez, A. (1905): La Mancha en tiempos de Don Quijote. Conferencia Real Soc. Geográfica. Madrid, Imp. Artillería, 1905, $31 \mathrm{pp}$.

(4) Caro Baroja, J. (1952): «Disertación sobre los molinos de viento», Revista de Dialectología y Tradiciones populares, cuad. $2 .^{\circ}$, pp. 212-266.

(5) - (1954): Norias, azudas y aceñas. Madrid, Centro de Estudios de Etnología peninsular, $160 \mathrm{p}$.

(6) Cebrián Abellán, A., y Cano Valero, J. (1992): Relaciones Topográficas de los pueblos del Reino de Murcia (1575-1579). Universidad, 1992, 468 pp.

$$
-323-
$$


(6 bis) Costa Mas, J. (1977): El Marquesat de Dénia. Estudio geográfico. Valencia, Universidad, $595 \mathrm{pp}$.

(7) Esteban Chapapría, J., y Sicluna lletget, R. «La ciutat de Valéncia y la seua arquitectura vista por van den Wijngaerde en 1563», pp. 99-148, en V. Roselló, dir. Les vistes valencianes d'Anthonie Van den Wijngaerde (1563).

(8) Flores, C. (1974): Arquitectura popular española. Madrid, Aguilar, 957 pp.

(9) García Mercadal, F. (1930): La casa popular en España. Bilbao, 93, p., 70 lám.

(10) González TAscón, I. (1987): Fábricas hidráulicas españolas. Madrid, Biblioteca Cehopu, Mopu, $536 \mathrm{pp}$.

(11) Jessen, O. (1965): «La Mancha. Contribución al estudio geográfico de Castilla la Nueva», trad. J. Gómez de Llarena (original 1930), Estudios Geográficcos, n. ${ }^{\circ}$ 98, pp. 88-125.

(12) KaGAN, R. L. (1986): dir. et al.: Ciudades del Siglo de Oro. Las vistas españolas de Anton Van den Wyngaerde. Madrid, El Viso, 1986, 427 pp.

(13) López Gómez, A. (1998): La navegación por el Tajo. El reconocimiento de Carduchi en 1641 y otros proyectos. Madrid, Real Academia de la Historia, $213 \mathrm{pp}$.

(14) López Gómez, J., y López Gómez, A. (1990): «La casa rural en Ciudad Real según las Relaciones Topográficas de Felipe II», Estudios Geográficos, n. 199-200, pp. 219-240.

(15) _ _ _ - (1992): «La vivienda rural toledana en el siglo XVı según las Relaciones Topográficas de Felipe II», Bol. Real Academia de la Historia, CLXXXIX, cuad. I, pp. 1-21.

(16) López Gómez, J., López Gómez, A. y Arroyo Ilera, F.: «La casa rural en Cuenca en el siglo XVI según las "Relaciones Topográficas de Felipe II"», pp. 389-401, vol. I, en V. Cabero (1992) et al., coords.: El medio rural español. Cultura, paisaje, naturaleza. Homenaje a don Ángel Cabo Alonso. Univ. Salamanca-Centro Est. Salmantinos.

(17) López PIÑERo, J. (1979): Ciencia y Técnica en la sociedad española de los siglos XVI y XVII. Barcelona, Labor, 512 pp.

(18) Madoz, P. (1845-1850): Diccionario geográfico-estadístico-histórico de España... Madrid, 16 vol.

(18 bis) MoRAl ItUARTE, L. del: La obra hidráulica en la cuenca baja del Guadalquivir (siglos XVIII y XIX). Sevilla, Univ. Sevilla-Consej. Obras Públicas-Ministerio Obas Públicas.

(19) Planchuelo Portales, G. (1958): Estudio del Alto Guadiana y de la altiplanicie del Campo de Montiel. Instituto Estudios Manchegos, 189 pp.

(20) Roselló i Verger, V. M.(1964): Mallorca. El Sur y Sureste. Palma de Mallorca, Cámara de Comercio, Industria y Navegación, 553 pp.

(21) - (1989): «Els molins d'aigua de l'Horta de València», pp. 317-345 en Los Paisajes del agua. Libro jubilar dedicado al profesor Antonio López Gómez. Univ. de ValenciaUniv. de Alicante, $394 \mathrm{p}$.

(22) ROSSElló I VERger, V. M. (1990): dir. et al., Les vistes valencianes d'Anthonie van den Wijngaerde (1563). Valencia, Consellería de Cultura, Educació y Ciència, 363 pp.

(23) TeIxidor DE OTTo, M. ${ }^{a}$ J.: «Les vistes de la ciutat de València», pp. 43-98, en Rosselló, dir., Les vistes valencianes d'Anthonie van den Wijngaerde...

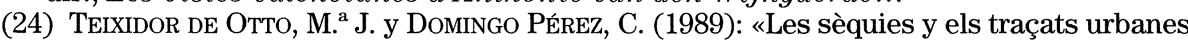
a València», pp. 287-301 en Los paisajes del agua. Libro jubilar... Antonio López Gómez. Univ. Valencia-Alicante, 1989.

(25) Torres Balbas, L. (1933): «La vivienda popular en España», pp. 137-502, en F. Carreras Candi, dir., Folklore y costumbres de España, Barcelona, Alberto Martín, vol. III.

(26) VIÑAS, C., y PAZ, J. (1949-71): Relaciones histórico-geográfico-estadísticas de los pueblos de España hechas por iniciativa de Felipe II. Madrid, Institutos Balmes y Sebastián Elcano (CSIC), 5 vol.: Madrid, Toledo (3 vol.) y Ciudad Real.

(27) Zarco Vacas y Cuevas, E. J. (1983): Relaciones de los pueblos del obispado de Cuenca hechas por Felipe II. Cuenca, 1927, 2 vol. Nueva ed. facs. preparada por D. Pérez Ramírez, Cuenca, Dip. Provincial, 1983, 685 p.

$$
-324-
$$

